\title{
El problema ambiental, el mercado de la moda y el diseño de experiencios como incentivo de consumo
}

Lissette Muñoz*

\section{Resumen}

El medio ambiente se ha afectado considerablemente debido a la actividad humana de las últimas décadas. La industria de la moda es uno de los sectores que más ha contribuido a la degradación de entorno, debido a que su mercado depende de la producción y consumo de cantidades enormes de materias primas que, en su mayoría, tienen procesos de degradación muy extensos. Además, hablamos de una industria que está presente en cualquier parte del mundo. Desafortunadamente, esta situación ha empeorado considerablemente con el surgimiento de fenómenos como la "pronta moda" que hace aún más desechables a las prendas de vestir. En este artículo de reflexión se abordan estos problemas en medio de una discusión centrada en los conceptos de diseño emocional y positivo. Esta reflexión arroja luces sobre el problema que está enfrentando la humanidad, particularmente catapultado por el campo de la moda, y aspira a convertirse en un material de referencia para el desarrollo de investigaciones futuras sobre el asunto.

Palabras clave: consumo, diseño positivo, emocionalidad, moda sustentable, sostenibilidad

\begin{abstract}
In recent decades, the global environment has been affected considerably due to human activity. The fashion industry is one of the sectors that has contributed to the degradation of the environment due to the fact that its market depends on the production and consumption of enormous quantities of raw materials. Additionally, fashion is an industry that is present in any part of the world. This situation has been worsening due to the emergence of phenomena such as the fast fashion that makes garments more disposable. In this paper of reflection, these problems are addressed by associating them with discussions supported on the concepts of emotionally durable design and positive design. This reflection sheds light on the problem that humanity is facing particularly in the field of fashion that can be the basis for the development of research on the issue.
\end{abstract}

Keywords: consumption, emotionality, positive design, sustainability and sustainable fashion

\footnotetext{
* Docente investigadora del programa de Diseño de Moda en la Coorporación Unificada Nacional de Educación Superior (cun). Contacto: lissette_munoz@cun.edu.co
} 


\section{El problema: consumismo y moda}

El devenir de la humanidad sobre la Tierra ha traído consigo el aumento progresivo $\mathrm{y}$ descontrolado del consumo de recursos naturales y de energía. Este fenómeno se aceleró con el surgimiento de la Revolución Industrial, el uso de combustibles fósiles, el crecimiento exponencial de la población y de su longevidad, y el incremento del ingreso económico promedio, particularmente a partir del siglo XIX y durante el florecimiento de las sociedades contemporáneas en el siglo xx.

\section{De la experiencia al consumo}

En términos económicos, el aumento desmedido del consumo puede explicarse por el surgimiento paulatino de nuevas necesidades humanas de bienestar ligadas a lo propiamente fisiológico y a lo placentero. También existe evidencia, por ejemplo, de que la publicidad puede llegar a moldear el comportamiento de los individuos al punto de que estos empiecen a manifestar un mayor deseo de consumo por determinados productos, por supuesto, sin que en este proceso participe ninguna necesidad natural real. Más bien, lo que allí salta a la vista es la pretensión de alcanzar un estatus particular o, en términos generales, de hacerse con cierta identidad que solo parece construirse a partir del consumo de productos. Esta atención hacia el consumo también está ligada a la idea según la cual la riqueza material se erige como el único camino directo al placer, concepción que abrió una perspectiva particular en el campo del diseño, dado que los productos de consumo también son recursos. Esta mezcla de causalidades desemboca finalmente en un efecto nefasto sobre el entorno de donde se extraen los recursos para desarrollar los productos y servicios con los que contamos en la sociedad actual (Chapman, 2005). Con esta problemática en mente, resulta interesante preguntarse qué incentiva, desde el
Actualmente, una de las preocupaciones más acuciantes para nuestra especie es, precisamente, que lo hecho durante los últimos dos siglos parece no tener reversa. La existencia de esta situación no tiene lugar a duda; muestra de ello son las estadísticas que pueden encontrarse en las bases de datos de organismos internacionales de considerable prestigio, por ejemplo, United Nations-un, Hábitat, Green Peace, por mencionar tan solo unas pocas.

punto de vista del diseño, el aumento observable del consumo de bienes materiales como las prendas de vestir.

Ahora bien, recordemos que la publicidad no solo se limita al hecho de incentivar considerablemente el consumo, pues también entra a desempeñar un papel central en lo que hoy se denomina experiencia de compra al ampliar su espectro a terrenos sensoriales. En esencia, su intención es seducir al comprador a través de una batería de elementos adicionales, dispuestos implícitamente en los lugares de ventas, que complementa la esencia de las marcas $(v \cdot g$. olores, estimulación visual, actividades adicionales) y que mejora y amplifica significativamente la necesidad de compra. Estas acciones se ejecutan con el fin de dirigir toda la experiencia de compra hacia un enfoque hedónico que busca resultados positivos y emociones agradables, así como suprimir las posibles impresiones negativas y reducir el disgusto del comprador, lo que, a su vez, contribuye a su bienestar (Desmet y Pohlmeyer, 2013). En este orden de ideas, se podría deducir que dentro de la concepción de la prenda está contemplada la posibilidad de producir felicidad a quien la adquiera, al menos en el momento de la compra. Pero, al final, lo que verdaderamente 
se espera es un incremento de la demanda de los productos impulsados por medio del diseño de experiencias. Esto podría estar muy ligado al denominado diseño positivo, que se basa en las ideas de la psicología positiva para crear y mejorar productos y servicios al aumentar su carácter de desarrollo humano (Desmet y Pohlmeyer, 2013).

Es interesante encontrar los límites del bienestar que el diseño positivo puede prodigar en calidad de generador de bienestar y al proporcionar experiencias en centros de venta de productos. El deseo que pueden producir los estímulos

\section{Basura inconsciente}

Si se analiza el problema en el marco del contexto global, esto es, a la luz del aumento insostenible del consumo y su consecuencia lógica sobre la depredación del medio ambiente - especialmente en lo tocante a los productos relacionados con la industria de la moda (vestuario, calzado, accesorios, servicios relacionados) y su uso generalizado - , nos enfrentamos al caso particular de una sociedad, la contemporánea, que no solo busca satisfacer sus necesidades físicas de abrigo y protección, sino también la búsqueda de estatus y de identidad.

Como ya ha sido comprobado en más de una oportunidad, buena parte de los productos que utilizamos hoy en día demandan enormes cantidades de recursos naturales para su fabricación y, por lo general, no están enmarcados dentro de los que se incluyen en los procesos de reciclaje, hecho que conlleva que, al final de su vida útil, sean desechados usualmente como basura (Woolridge, Ward, Phillips, Collins y Gandy, 2006). En este punto es posible observar un inconveniente significativo que ha dado paso al interés para desarrollar el presente artículo muchas veces deviene en un eficaz detonante de compra. Pues bien, al respecto cabe decir que no es el deseo el que se apoya en las necesidades, sino al contrario, son las necesidades las que se derivan del deseo: son contraproductos en lo real que el deseo produce. La carencia de un contraefecto del deseo está depositada, dispuesta, visualizada en lo real natural y social. Para ponerlo en términos de Deleuze y Guattari (1973), el deseo siempre se mantiene cerca de las condiciones de existencia objetiva, se las adhiere y las sigue, no sobrevive a ellas, se desplaza con ellas.

de reflexión, cuya función, como se desprende del planteamiento del problema, es concientizar sobre la necesidad de iniciar una discusión sobre cómo podemos enfrentar con urgencia el consumo desbordado en la industria de la moda y en los campos relacionados.

Al campo del diseño de moda ha llegado recientemente la discusión sobre la problemática de la producción desmedida de prendas $y$, con ella, la ausencia de una conciencia plena de todas las afectaciones ocasionadas por su compra, uso y, todavía más grave, desecho. Con respecto a la última instancia del ciclo vital de la ropa no se ha dicho mucho: casi nula es la importancia que generalmente se le da cuando, ya convertida en residuo, llega al ambiente sin mayor control. Es sorprendente que, hace diez años, esta no era una cuestión que suscitara mayor reflexión consciente o intencional. En ese momento, para un diseñador de moda resultaba irrelevante pensar si las prendas que producía tendrían con el tiempo un desgaste, un envejecimiento, si serían desechadas antes o después de este proceso, si sencillamente harían parte de un 
enorme basurero o si sus productos llegarían alguna vez a descomponerse totalmente.

Cuando por fin se tomó la decisión de prestar atención a este tipo de problemas, surgió, de la mano, el interés de introducir un pensamiento más sostenible y tomar seriamente, como propia, la idea de implantar en la discusión el concepto conocido como moda sostenible. Este cambio radical en la forma de pensar se ha dado, en gran medida, por las diversas manifestaciones que el mundo ha puesto sobre la mesa como muestra de la industrialización de la moda y, en general, porque se hizo evidente que la industria necesita cambiar tanto sus formas de producir y diseñar, como su modo de intervenir y generar cambios a través de sus propios objetos.

Este cambio de conciencia es del que hablan libros tan centrales como Emotionally Durable Design: Objects, Experiences y Empathy de Jonathan Chapman, como se puede ver, construido alrededor del concepto de emocionalidad. Chapman, al ampliar y redirigir la perspectiva, nos invita a pensar el proceso de reciclaje de los objetos desde la emocionalidad, es decir, desde el ejercicio mismo del diseño y su proceso creativo. La idea es desarrollar objetos que se erijan como nuevos puntos de inicio, esto es, que establezcan lazos sentimentales con sus dueños o simplemente planteen una estrategia para que esa conexión emocional entre el objeto y el usuario se traduzca en un uso más prolongado de ellos - el usuario pensará dos veces la idea de desechar un producto con el que está enlazado emocionalmente-. De esta forma, la prolongación del uso del recurso podría reducir significativamente la necesidad de consumir más. Chapman se planteó la idea de un diseño durable y emocional a partir de la siguiente pregunta: ¿por qué los usuarios desechan productos que aún funcionan?
El pensamiento de Chapman cambia la perspectiva sobre la implementación del diseño emocional, pues no apunta solamente hacia la creación de conexiones instantáneas y pasajeras entre los productos y las personas para crear bienestar, sino que plantea la posibilidad real de generar verdaderas conexiones emocionales que perduren en el tiempo, por medio de una reevaluación de la misión y visión del diseño. Ahora bien, hablar de las conexiones emocionales como estrategias que aportan a la sostenibilidad puede sonar un poco inverosímil. Esto se debe, en gran parte, al hecho de que la dimensión de lo emocional no puede hacerse tangible o materializarse de formas concretas. No obstante, cabe decir a su favor que esta tiene una gran incidencia a la hora de pensar los modos posibles para extender el ciclo vital de los productos, pues estos tienden a durar mucho más si establecen vínculos fuertes con las personas. En efecto, la propuesta de Chapman es una clara toma de posición frente a la obsolescencia programada.

En tiempos no muy lejanos, a finales de los ochenta y noventa, todavía era posible observar cómo las personas frecuentemente alargaban la vida de sus prendas al remendar con cuidado y esmero lo averiado, o cómo los padres de familia consumían su fin de semana en la reparación de los electrodomésticos. Esta lógica se privilegiaba, en parte, por el ahorro que traía implícito, pero, en un sentido más profundo, se seguía como un credo por la necesidad de cuidar y preservar el valor emocional que iban adquiriendo los objetos que componían los hogares -algunos incluso llegaban al punto de erigirse en verdaderos patrimonios familiares-.

Sin embargo, estas tradiciones fueron sustituidas por la idea del denominado progreso al estilo consumista. Este trajo consigo la avalancha de las nuevas tecnologías, por lo general, a muy 
bajo costo y reforzadas con las facilidades de los créditos bancarios. Esta dinámica impulsó la lógica de la compra desmedida y sin vínculos emocionales, aquella que muchas veces nos incita a adquirir cosas que ya tenemos o que simplemente no nos hacen falta. En comparación con lo que sucedía antes, sin perder por ello el horizonte de las diferencias históricas, hoy en día observamos que las necesidades básicas ya no representan el límite del consumo: los deseos lo abarcan todo; el mundo está al alcance de todos gracias a los smartphones. La vida de cualquier persona parece estar conectada allí, al lugar donde puede tener acceso fácilmente a todo tipo de información y productos. Ahora, con esto no se quiere decir que el progreso y sus nuevas tecnologías son intrínsecamente negativos; solo queremos sugerir que en muchas situaciones se están saliendo de control.

Todo parece estar enlazado en un entramado de hechos y consecuencias. La industria conoce de nuestros deseos: nos observa a través de las redes sociales para capturar nuestras preferencias, cada vez con mayor precisión. En este sin fin de redes sociales en las cuales nos hacemos evidentes, somos una suerte de Pinterest de deseos, un Instagram de momentos, un Facebook de exhibición; mostramos una vida para que una industria diseñe nuestros deseos y luego nos los venda. Paradójicamente, también lo natural es comercializado de forma infortunada. Como dicen Deleuze y Guattari, “es probable que, a un determinado nivel, la naturaleza se distinga de la industria: por una parte, la industria se opone a la naturaleza, por otra, saca de ella materiales, y por otra, le devuelve sus residuos" (1973, p. 25). Este tipo de relaciones que tenemos con la naturaleza - y esta, a su vez, con la industriaevidencia lo poco que sabemos de su intimidad y delicadeza, aun a pesar de que nos abarcan $\mathrm{y}$ nos hacen partícipes en todo momento. Así, nos aferramos a justificarnos para poder desentendernos del verdadero impacto que produce el hecho de tomar de la naturaleza los recursos que procesamos y devolvemos fundamentalmente en forma de basura.

La sostenibilidad representa un universo de oportunidades considerables para el campo de la moda. Si bien, este también es vulnerable a los conflictos ambientales que cualquier otro sector pensado y fabricado por el hombre puede tener, no puede desconocerse que tiene un elemento diferencial de gran importancia para esta discusión, a saber, el hecho de que la moda está hecha de fantasía: hablamos de una industria pensada para el momento, para el disfrute, para el placer visual y material, para la actualidad. Con una equilibrada carga de fascinación y horror, resulta interesante observar esa otra parte que la moda podría ofrecer, por supuesto, sin dejar a un lado su toque de originalidad. Hablo, en concreto, de contemplar la posibilidad de diseñar con prendas ya usadas, de crear con lo que ya está, de alargar la vida de las prendas o de posiblemente usar lo que poco se vende o lo que nunca se vendió para crear algo nuevo. 


\section{Referencias}

Chapman, J. (2005). Emotionally Durable Design: Objects, Experiences y Empathy. Estados Unidos: Routledge.

Deleuze, G. y Guattari, F. (1973). El Anti-Edipo. Capitalismo y esquizofrenia. Buenos Aires: Paidós.

Desmet, P. y Pohlmeyer, A. (2013). Positive Design: An Introduction to Design for Subjective Well-Being. International Journal of Design, 7(3), 5-19. Recuperado de https:/ / bit.ly/2O9g3eC

Woolridge, A., Ward, G., Phillips, P., Collins, M. y Gandy, S. (2006). Life cycle assessment for reuse/recycling of donated waste textiles compared to use of virgin material: an UK energy saving perspective. Resources, Conservation and Recycling, 46(1), 94-103. Recuperado de https:/ / bit.ly/2Oar27N 